\title{
IMPACTOS DA PRODUÇÃO ALGODOEIRA NA ECONOMIA DE MATO GROSSO - 2007
}

\author{
Felipe Deodato da Silva e Silva ${ }^{1}$ \\ Dirceu Grasel ${ }^{2}$
}

\begin{abstract}
RESUMO: A finalidade desta pesquisa é analisar comparativamente os impactos econômicos decorrentes da produção de algodão na economia de Mato Grosso, por meio da Matriz Insumo-Produto de Leontief, que foi construída com base no ano de 2007. Foram abordados conceitos de cadeia produtiva e agronegócio para compreender teoricamente a estrutura produtiva de um setor específico como a agricultura. Foram utilizados os índices de ligação (linkages) de Rasmussen/Hirschman e os Multiplicadores de Produção, Emprego e Renda para estimar os impactos econômicos. Percebeu-se que a atividade algodoeira sofreu influência da Lei Kandir e do aumento de produtividade resultando num crescimento produtivo acelerado nas últimas duas décadas. Apesar dos impactos econômicos significativos para a economia do estado, a produção algodoeira não apresentou indicadores que a colocasse como uma atividade chave na cadeira produtiva nem como um setor capaz de dinamizar a economia mato-grossense. Deve-se isso ao fato da cadeia produtiva do algodão em Mato Grosso restringir-se à produção agrícola e desenvolvendo-se pouca a industrialização. Acredita-se que incorporando demais elos como as indústrias de insumos agrícolas e de processamento do algodão, o setor possa apresentar um potencial maior de influência no crescimento econômico estadual.
\end{abstract}

Palavra-chave: Cotonicultura, Mato Grosso, Matriz Insumo-Produto.

ABSTRACT: The objective of this research is analyse comparatively the economic impacts of cotton production in Mato Grosso economy, through of the matrix Input-Output of Leontief that was built based on 2007 year. Was discussed the concept of supply chain and agribusiness to understand theoretically the production structure of a specifically sector of economy as agriculture. Was used the linkages indicator Rasmussen/Hirschman and the multipliers production, employment and income to estimate de economic impacts. It was noticed that the cotton activity was influenced by Kandir law and the increase of productivity resulting in an accelerated productive growth in the last two decades. Despite of relevant economic impacts to state economy, the cotton production did not present indicator that put as a key activity in the supply chain neither as a sector able to boost the Mato Grosso economy. It must to the fact of the cotton supply chain in Mato Grosso restricted to agricultural production and development in some the industrialization. It is believed that incorporating others links as the agricultural input and cotton processing industry, the sector could present a potential higher of influence in the state economy growth.

Key-words: cotton industry, Mato Grosso, Input-Output pattern.

\footnotetext{
${ }^{1}$ Faculdade de Economia da Universidade Federal de Mato Grosso. E-mail: felipe_futuro@yahoo.com.br

${ }^{2}$ Faculdade de Economia da Universidade Federal de Mato Grosso. E-mail:
}

Recebido em: 16/04/2012

Aceito em: 08/06/2012 


\section{INTRODUÇÃO}

A economia é um sistema interligado no qual suas partes se relacionam fazendo com que qualquer mudança em algum setor resulte em impactos nos demais setores da economia, mesmo não estando diretamente interligados. Cada empresa está conectada com outras estabelecendo relações de compra e venda, seguindo a lógica do imput-output. Essa ideia também está presente em setores como a agricultura, ou mais especificamente a cotonicultura, cujas empresas demandam insumos agrícolas e ofertam algodão para outras empresas de outros setores.

Um investimento no sistema produtivo gera um aumento na demanda por insumos e mão-de-obra, que são os principais fatores de produção, e tem por consequiência um aumento de produção (Keynes, 2007). Esse fato é conhecido na Ciência Econômica como o efeito multiplicador, que em outras palavras, são investimentos que geram efeitos dentro e fora da cadeia produtiva. Para compreender esses impactos foram elaborados conceitos teóricos, como cadeia produtiva ou "filière" da escola francesa, e instrumentos metodológicos, como a matriz insumo-produto de Leontief, para auxiliar no entendimento das relações existentes entre atividades econômicas (BATALHA, 2007).

Por conta dessa evolução nos estudos setoriais, a visão que os economistas tinham de alguns setores foi alterada, principalmente da agricultura, que passou a ser vista, não como um setor isolado, mas como uma atividade interrelacionada e relevante para o desenvolvimento econômico. Segundo Lewis (2011), em alguns casos específicos em que a agricultura apresente produtividade marginal nula, esta pode auxiliar no desenvolvimento industrial como fornecedora de mão-obra. Além disso, segundo Johnston e Mellor (1961) a agricultura possui algumas funções que auxiliam no desenvolvimento econômico de uma nação tais como, fornecimento de matéria-prima e mão-de-obra, produção de alimentos, fibras e energia, e mercado para produtos industrializados.

Considerando as diversas formas como uma determinada atividade pode se relacionar com as demais, é possível compreender as causas dos impactos de cada conexão intersetorial e a partir dos instrumentos metodológicos é possível mensurar esses impactos na cadeia produtiva. O aspecto da mensuração é possível graças ao modelo de matriz insumo-produto de Leontief, onde se encontram os coeficientes técnicos que são usados 
para estimar os índices de multiplicadores da produção, do emprego e da renda em cada um dos setores (FIGUEIREDO, 2003).

Com isso, a questão central desta pesquisa é verificar como se dão as conexões entre os setores de uma economia e assim mensurar os impactos econômicos, no aspecto da produção e da geração de emprego e renda, que são relevantes dentro de uma perspectiva regional. Para isso, é necessário determinar um campo de estudo cuja atividade seja importante e esteja relacionada a outros setores num espaço regional específico. Em meio a essa discussão, este artigo se propõe a analisar comparativamente o setor da cotonicultura no Estado de Mato Grosso, considerando seus impactos econômicos de produção, emprego e renda na economia como um todo. Para atingir esse objetivo, será utilizado a matriz insumo-produto de Leontief construída para o Estado de Mato Grosso e Brasil para o ano de 2007.

Inicialmente será realizado uma breve discussão teórica a respeito dos conceitos de cadeia produtiva (filière) e agronegócio (agribusiness), e da evolução metodológica da matriz-insumo produto. Logo em seguida, será realizado um relato sobre o setor produtivo do algodão dentro na economia de Mato Grosso, considerando o histórico do crescimento produtivo do setor. Adiante, serão analisadas as informações obtidas pela matriz insumoproduto do Estado de Mato Grosso, para o ano de 2007, focando na produção algodoeira e seus impactos econômicos na produção e na geração de emprego e renda na economia como um todo.

\section{CADEIA PRODUTIVA, AGRONEGÓCIO E MATRIZ INSUMO-PRODUTO}

A forma de se analisar o encadeamento dos setores assim como a mensuração dos impactos econômicos teve como principais vertentes teórico-metodológicas a escola francesa, no desenvolvimento do conceito de cadeia produtiva, a escola americana, que definiu o termo agronegócio, e a matriz insumo-produto de Leontief. A seguir será realizada uma breve discussão a respeito desses conceitos. 


\subsection{Cadeia produtiva e agronegócio}

Segundo Batalha (2007), uma das vertentes mais importantes na análise setorial tem origem nos Estados Unidos, com os estudos de Davis e Goldberg, que elaboraram o conceito de agribusiness (agronegócio). Além disso, outra vertente surgiu na década de 60 no âmbito da escola industrial francesa cuja análise era focada na "filière", ou seja, na cadeia produtiva. Assim, a agricultura passou a ser vista como componente importante de um sistema mais amplo, no qual se encontra interligada com outros setores da economia, como a indústria e o comércio. Com isso, a agricultura ganhou mais ênfase nas análises de desenvolvimento e crescimento econômicos, como mostra Lewis (2011) e Johnston e Mellor (1961).

O agronegócio é visto como um sistema complexo que envolve não apenas as atividades de dentro da propriedade rural, mas também as que ocorrem fora desse âmbito (MENDES e BATISTA Jr., 2007). Por isso, esse conceito inclui etapas que vão desde o mercado de produtores de insumos agrícolas (indústria de máquinas e equipamentos, fertilizantes, agrotóxico, sementes, entre outros) até o consumidor final no varejo. Pelo fato dessas atividades estarem conectadas dentro de uma sequencia de produção, qualquer alteração na produção agrícola poderá desencadear alterações nas demais atividades.

A cadeia produtiva (filière) se aplica à sequência de atividades que transforma uma commodity em um produto final para o consumidor. $O$ enfoque da cadeia é a hierarquização e o poder de mercado, analisando a dependência dentro do sistema em relação às estruturas de mercado e às forças externas, como o governo (ZYLBERSZTAJN, 2000). Uma diferença entre Agronegócio e Cadeia Produtiva apontada por Zylberstajn (2000), é que a abordagem americana prioriza as estratégias das corporações, já a outra enfatiza as ações governamentais.

Entretanto, as duas abordagens surgem tendo como base metodológica a Matriz Insumo-Produto de Leontief por enfatizar as relações intersetoriais, mas que acaba possuindo limitações por não incorporar o avanço tecnológico. A estrutura da matriz segue na concepção da função de produção neoclássica com coeficientes técnicos fixos, e por isso não é um instrumental adequado para analisar o aspecto tecnológico da cadeia produtiva. Entretanto, o foco desta pesquisa não é analisar a questão tecnológica e sim os impactos econômicos decorrentes da produção de algodão em Mato Grosso, e neste caso a limitação inerente à matriz não se configura um empecilho. Além disso, o enfoque se dá no 
crescimento econômico decorrente dos impactos do setor algodoeiro que reflete na economia mato-grossense como um todo.

\subsection{A matriz insumo-produto de Leontief}

O desenvolvimento da matriz insumo-produto por Leontief teve como base os estudos iniciados por François Quesnay em seu livro Tableau Économique, que representa o início dos estudos da interdependência das atividades econômicas (ROSSETTI, 1995). As primeiras matrizes construídas foram para a economia norte-americana na década de 30, época em que Leontief se tornou professor da Universidade de Harvard. Essas matrizes foram publicadas em 1936 e 1937, sendo uma evolução importante para a teoria econômica, resultando no prêmio Nobel de Leontief em 1975 (FIGUEIREDO, 2003).

O modelo de Leontief consiste na interrelação entre insumo e produto no sistema produtivo, e por isso, foi amplamente aceito como instrumento de planejamento econômico e um importante guia nas tomadas de decisões dos países (FIGUEIREDO, 2003). Um breve relato sobre o histórico da matriz é importante, mas não configura o foco deste trabalho, por isso, a próxima seção será dedicada ao aspecto metodológico da Matriz Insumo-Produto, enfatizando os elementos de sua construção, os coeficientes técnicos, os Índices de Ligação Rasmussen e Hirschman e os Multiplicadores do Tipo I de Produção, Emprego e Renda.

\section{O MÉTODO DA MATRIZ INSUMO-PRODUTO}

\subsection{Cálculo da inversa de Leontief}

A Matriz de Leontief demonstra a interrelação entre os setores de uma economia, numa perspectiva input-output. Essa relação é do tipo oferta/demanda, ou seja, um setor oferta e o outro demanda a sua produção. 
Quadro 1 - Exemplo de uma Matriz Insumo-Produto.

\begin{tabular}{|l|c|c|c|c|c|c|}
\hline & $\begin{array}{c}\text { Setores } \\
\text { Compradores }\end{array}$ & $\begin{array}{c}\text { Consumo } \\
\text { Familias }\end{array}$ & Governo & Investimento & Exportações & Total \\
\hline $\begin{array}{l}\text { Setores } \\
\text { Vendedores }\end{array}$ & $\mathrm{Z}$ & $\mathrm{C}$ & $\mathrm{G}$ & $\mathrm{I}$ & $\mathrm{E}$ & $\mathrm{X}$ \\
\hline Importação & $\mathrm{M}$ & $\mathrm{Mc}$ & $\mathrm{Mg}$ & $\mathrm{Mi}$ & & $\mathrm{M}$ \\
\hline Impostos & $\mathrm{T}$ & $\mathrm{Tc}$ & $\mathrm{Tg}$ & $\mathrm{Ti}$ & $\mathrm{Te}$ & $\mathrm{T}$ \\
\hline $\begin{array}{l}\text { Valor } \\
\text { Adicionado }\end{array}$ & $\mathrm{W}$ & & & & & $\mathrm{W}$ \\
\hline Total & $\mathrm{X}$ & $\mathrm{C}$ & $\mathrm{G}$ & $\mathrm{I}$ & $\mathrm{E}$ & \\
\hline
\end{tabular}

Fonte: Figueiredo (2003).

De acordo com Figueiredo (2003):

Z é o fluxo monetário entre os setores da economia;

C é o consumo dos produtos dos setores pelas famílias;

G e o gasto do governo junto aos setores;

I é a demanda por bens de investimento produzidos nos setores;

E é o total exportado pelos setores;

$\mathrm{X}$ é o total de produção dos setores;

T é o total de impostos indiretos líquidos pagos pelos setores;

M é a importação realizada pelos setores;

W é o valor adicionado gerado pelos setores.

O Quadro 1 exemplifica o que seria uma matriz insumo-produto. Os setores da vertical são responsáveis por vender para os setores da linha superior, e também para as famílias, para o governo, para a demanda de investimento e para as exportações (regiões exógenas). A coluna referente ao Total representa o valor da produção do setor, os totais de importação e tributação, e o valor adicionado.

Com essa matriz pode-se estabelecer a igualdade a preços correntes de mercado:

$$
X+C+G+I+E=X+M+T+W
$$

No qual exclui dos dois lados o valor de $\mathrm{X}$,

$$
C+G+I+E=M+T+W
$$

Onde podemos estabelecer outra igualdade macroeconômica: 


$$
C+G+I+(E-M)=T+W
$$

Dessa forma, o valor da produção de cada setor $(\mathrm{X})$ é representado pela demanda total, que pode ser subdividida entre a demanda dos demais setores ( $\mathrm{z}$ ) e a demanda final $(\mathrm{Y})$.

$$
X=z 1+z 2+\cdots+z n+Y
$$

Com isso, pode-se estabelecer um coeficiente técnico de proporcionalidade entre os setores, representado por:

$$
a=\frac{z n}{x}
$$

Com os valores dos coeficientes técnicos estabelece a Matriz de Coeficientes Técnico (C), que pode ser representada de forma matricial:

$$
X=C X+Y
$$

No qual $\mathrm{X}$ representa o vetor dos valores da produção dos setores e $\mathrm{Y}$ o vetor referente à demanda final dos setores. Com isso, é possível realizar operações matriciais:

$$
X=A X+Y \quad \Rightarrow \quad X-A X=Y \quad \Rightarrow \quad X(I-A)=Y
$$

Onde I representa a matriz identidade e se a matriz (I-A) não for singular, pode-se invertê-la:

$$
\begin{aligned}
& X=(I-A)^{-1} Y \\
& D=(I-A)^{-1}
\end{aligned}
$$

A matriz $(\mathrm{I}-\mathrm{A})^{-1}$ é conhecida como a inversa de Leontief que será denotada como matriz $D$, onde é possível determinar o nível de produção necessária para atender a demanda final de cada setor.

\section{2 Índices de Ligação}

Os índices de ligação ou linkages foram elaborados por Rasmussen em 1956 e Hirschman em 1958 (apud FIGUEIREDO, 2003). Esses índices apontam o potencial de influenciar outras atividades de uma mesma cadeia produtiva, ou seja, em relação as 
relações de compra (índice para trás) e venda (índice para frente) da perspectiva inputoutput.

Valores acima de um (tanto para trás quanto para frente) indicam setores chaves para entender a dinâmica da cadeia produtiva, ou seja, se eles impactam significativamente nas demais atividades que estão interligadas. Mas para McGilvray (apud FIGUEIREDO, 2003) devem ser considerados setores-chaves aqueles que tiverem índice de ligação maior que um tanto para trás quanto para frente. Entretanto, para efeito de análise deste trabalho, serão considerados setores-chaves aqueles que obtiverem um dos indicadores com valor superior a um.

Dessa forma, o índice de Rasmussen e Hirschman para trás será calculado pela fórmula:

$$
I t=\frac{[D a j * n]}{D^{r}}
$$

Onde It será o índice para trás, Daj é a soma da coluna referente ao setor a, n o número de setores e D’ a soma de todos os elementos da matriz D.

Já o índice para frente é calculado da seguinte forma:

$$
\text { If }=\frac{[D a i * n]}{D r}
$$

Sendo, If o índice para frente, Dai é a soma da linha na matriz do setor a.

\section{3 Índices de impactos}

\subsubsection{Efeitos diretos e indiretos}

Os Efeitos Diretos (ED) são coeficientes que indicam a participação do setor em análise na atividade econômica como um todo, ou seja, a relação do valor de sua produção (a) com o valor da produção total da economia (A).

$$
E D=\frac{a}{A}
$$

Já o Efeito Indireto (EI) é o produto entre o coeficiente de Efeito Direto (ED) da atividade em questão com o coeficiente dessa mesma atividade na matriz inversa de Leontief (aL).

$$
E I=E D * a L
$$




\subsubsection{Multiplicadores}

Existem dois tipos de multiplicadores, o do Tipo I e II. Segundo (FIGUEIREDO, 2003), os multiplicadores do Tipo I consideram os efeitos diretos (sobre o próprio setor) e os indiretos (sobre os demais setores), já o Tipo II além de considerar os efeitos direto e indireto, incorpora os efeitos induzidos da demanda final (consumo das famílias). Para esta análise será considerado apenas do multiplicador do Tipo I.

Para fins de análise, serão calculados os multiplicadores referentes à Produção, Renda e Emprego, da Produção do Algodão em Mato Grosso. O multiplicador da produção se refere aos efeitos exógenos de produção resultantes do aumento na demanda final de um determinado setor (FIGUEIREDO, 2003). Já o multiplicador da renda é aumento da renda geral na economia decorrente do aumento da produção de um determinado setor devido a um aumento em sua demanda final (FIGUEIREDO, 2003). E por fim, o multiplicador do emprego representa o número de emprego gerado devido ao emprego gerado na atividade em análise, ou seja, representa o emprego indireto (FIGUEIREDO, 2003).

Assim, o multiplicador da produção será calculado,

$$
M P=D a j
$$

Onde, Daj é o somatório na coluna do setor a da matriz D. O multiplicador da renda será calculado,

$$
M R=\frac{E D r}{E I r}
$$

Sendo, EDr o Efeito Direto e EIr o efeito indireto sobre a renda. E por fim, o multiplicador do emprego será calculado por

$$
M E=\frac{E D s}{E I \theta}
$$

Cuja variável EDe representa o efeito direto e EIe o efeito indireto sobre o emprego.

\subsection{Impactos da cotonicultura em Mato Grosso}

A produção de algodão em Mato Grosso obteve elevado crescimento após a instituição da Lei Kandir, em setembro de 1996, que além de outras provisões, isentava os produtos primários do ICMS (Imposto sobre Circulação de Mercadorias e Prestação de 
Serviços), desde que fossem destinados a exportação no estado in natura. Isso trouxe como consequiência um aumento na área plantada que resultou no aumento da produção e do valor produzido no setor algodoeiro. Assim, cidades como Sapezal, Campo Verde e Primavera do Leste iniciaram a sua produção e atualmente se destacam como os principais municípios produtores de algodão. Nas seções seguintes será abordada a situação atual da cotonicultura do estado, como base em séries históricas obtidas no IBGE (2012), e também a sua relevância econômica para Mato Grosso decorrente dos índices de ligação e de impactos.

\subsection{A cotonicultura no estado de Mato Grosso}

O estado de Mato Grosso atualmente é o maior produtor de algodão do Brasil, correspondendo a 49,31\% da produção nacional (IBGE, 2012). Esse fato coloca o Estado no centro das discussões quando o assunto é a cotonicultura, pois sendo o maior produtor nacional, possui influência significativa neste setor, podendo ocasionar impactos econômicos em outros Estados. Entretanto, esta pesquisa será restringida aos impactos dentro de Mato Grosso.

È possível verificar (Figura 1) como a participação relativa da produção algodoeira mato-grossense se comporta entre os anos de 1990 a 2010. Entre os anos de 1990 a 1996 a participação da produção de algodão de Mato Grosso se torna praticamente estável, girando em torno de 5,52\% ao ano. Já entre os anos de 1997 a 2001, a cotonicultura apresenta um cenário expansivo de produção, crescendo a uma taxa média de 56,59\% ao ano principalmente influenciado pela Lei Kandir (1996). Por fim, entre os anos de 2002 a 2010 a produção se manteve com participação estável em relação à produção nacional, que obteve uma média de participação de 50,04\%.

Essa dinâmica mostra que o ano de 2007 esteve no centro de um cenário estável de participação da produção algodoeira brasileira, entre 2002 a 2010. A média de participação da produção de algodão do período 2002-2010 não foi tão diferente da participação de 2007, que foi de 53,63\%. Isso mostra que em relação à participação da produção matogrossense na produção nacional, 2007 não foi um ano atípico e sim um período em que a produção algodoeira seguiu a tendência que havia tomado desde 2002. 
Figura 1-Participação do Mato Grosso na Produção de algodão nacional - 1990 a 2010.

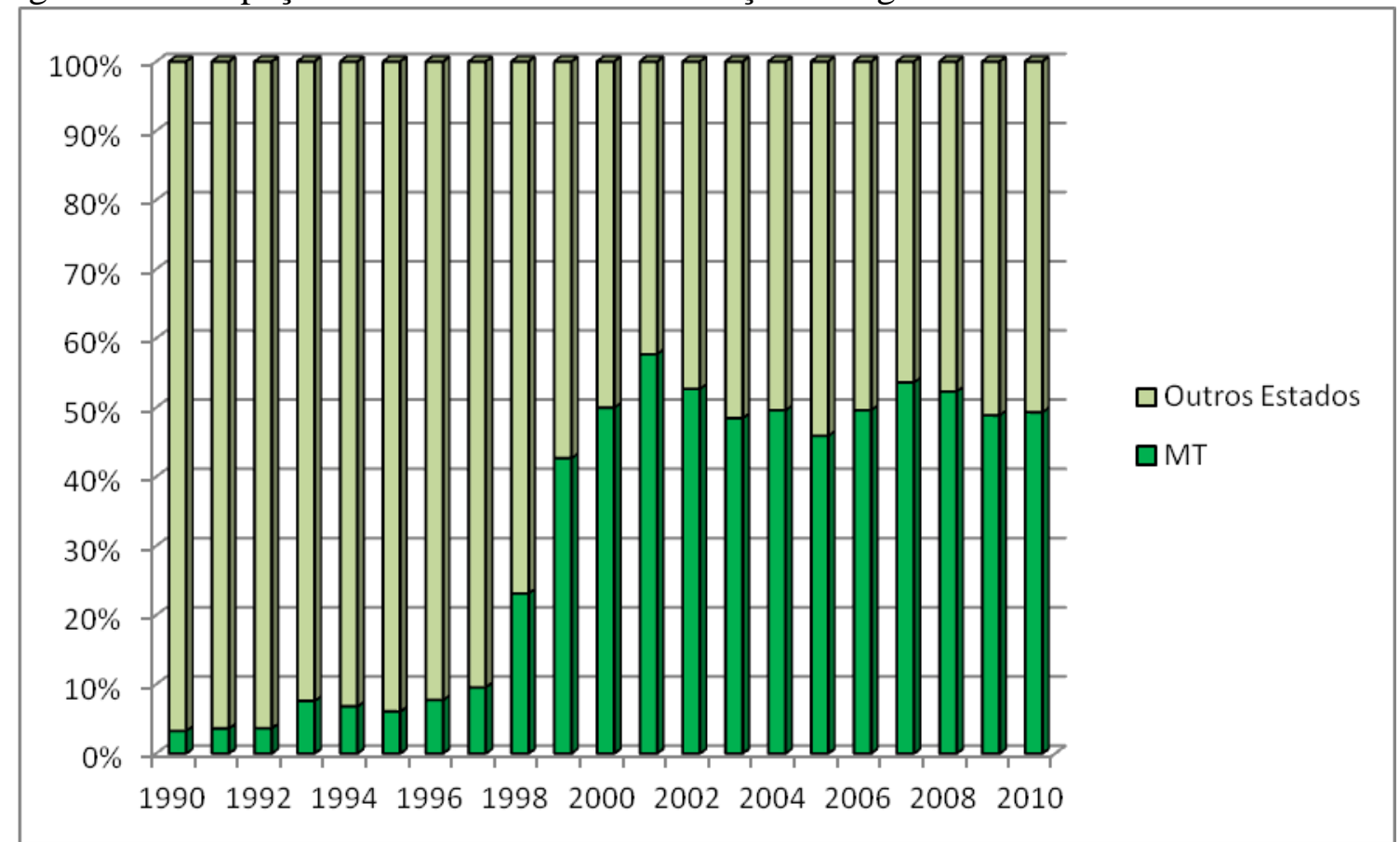

Fonte: Produção Agrícola Municipal/IBGE (2012).

Tanto a produção quanto a área destinada à cotonicultura de Mato Grosso teve uma crescimento significativo após a implantação da Lei Kandir (1996), fazendo com que alguns municípios do norte do estado se destacassem nesta cultura. No ano de 2010, Campo Verde foi o maior produtor, seguido por Sapezal e Pedra Preta. Campo Verde produz cerca de $13 \%$ da produção estadual, Sapezal corresponde a $11 \%$ e Pedra Preta $6,7 \%$, juntos correspondem a quase um terço, demonstrando a importância desses municípios para o setor.

Tabela 1. Produção de algodão (t) dos principais municípios de Mato Grosso em 2010.

\begin{tabular}{l|c|c}
\hline \multicolumn{1}{c|}{ Município } & Produção (t) & \% MT \\
\hline Campo Verde & $189.922,00$ & 13,06 \\
Sapezal & $165.600,00$ & 11,38 \\
Pedra Preta & $98.475,00$ & 6,77 \\
Diamantino & $92.957,00$ & 6,39 \\
Primavera do Leste & $84.354,00$ & 5,80 \\
Alto Taquari & $83.272,00$ & 5,72 \\
Campo Novo do Parecis & $61.243,00$ & 4,21 \\
Nova Mutum & $58.680,00$ & 4,03 \\
Alto Garças & $58.656,00$ & 4,03 \\
Dom Aquino Total & $58.626,00$ & 4,03 \\
\hline \multicolumn{2}{c|}{$\quad \mathbf{9 5 1 . 7 8 5 , 0 0}$} & $\mathbf{6 5 , 4 3}$ \\
\hline
\end{tabular}

Fonte: Produção Agrícola Municipal/IBGE (2012). 
A produtividade, que é a relação entre a produção (t) e a área plantada (ha), apresentou a mesma tendência que a produção entre os anos de 1990 a 2010 (Figura 1 e Figura 2). Entre os anos de 1990 e 1996 a produtividade media foi de 1,27 t/ha, já entre os anos de 1997 à 2001 a média foi de 3,03 t/ha e entre 2002 à 2010 foi de 3,73 t/ha. $\mathrm{O}$ ano de 2007 se manteve próximo à média do período 2002-2010, com uma produtividade de 3,93 t/ha. Embora a produtividade de 2007 esteja acima da produtividade média do período 2002-2010, considera-se que há pouca diferença, podendo dizer que em relação à produtividade, o ano de 2007 não se trata de um ano atípico para a produção de algodão. Destaca-se na Figura 2 que a produtividade de Mato Grosso esteve acima da produtividade nacional a partir do ano de 1996, que coincide com a aplicação da Lei Kandir.

Figura 2 - Índice de produtividade da produção de algodão de Mato Grosso de 1990 a 2010 (t/ha)



Fonte: Produção Agrícola Municipal/IBGE (2012).

Através desses dados é possível compreender a relevância de Mato Grosso como produtor do algodão, assim como 2007 que não foi um ano atípico. Entretanto, é preciso também mensurar os impactos econômicos que a produção algodoeira conseguiu produzir na economia mato-grossense, desde o mercado de insumos agrícolas até o mercado consumidor final. A seguir será realizada uma análise desses impactos econômicos na economia de Mato Grosso, focando principalmente na produção e geração de emprego e renda. 


\subsection{Análise dos indicadores de ligação (linkages) e de impactos econômicos}

Segundo McGilvray (apud FIGUEIREDO, 2003) um setor só será considerado chave dentro da cadeia produtiva se tiver um índice de ligação tanto para frente quanto para trás superior a um. Entretanto nessa pesquisa, será considerado setor chave se tiver pelo menos um dos índices superior a um, isso porque, um setor chave seria aquele capaz de influenciar na dinâmica econômica da cadeia produtiva, seja nas etapas anteriores ou posteriores à atividade analisada. Além disso, será analisado somente o multiplicador do tipo I que considera os efeitos diretos e indiretos da atividade selecionada e serão estimados os impactos econômicos na produção, no emprego e na renda. A escolha desse indicador se dá pela ausência de informações para o cálculo do multiplicador do tipo II, que traz a renda de forma endógena na matriz.

Ao estimar os índices de ligação (linkages) na cadeia produtiva de RasmussenHirschman dos principais setores da agricultura de Mato Grosso (Tabela 2), foi identificado que apesar de sua relevância a nível nacional, o setor do algodão possui índices inferiores a um que apontam uma atividade menos dinâmica que as demais atividades comparadas, tais como o arroz e a soja. $\mathrm{O}$ arroz mostrou-se chave para frente na cadeia produtiva, já a soja se mostrou chave para trás. $\mathrm{O}$ algodão e o milho não se mostraram setores chaves nem para frente nem para trás.

Tabela 2. Índices de Rasmussen-Hirschman dos principais setores agrícolas de Mato Grosso - 2007.

\begin{tabular}{l|c|c}
\hline \multirow{2}{*}{ Setores } & \multicolumn{2}{|c}{ Índice de Rasmussen-Hirschman } \\
\cline { 2 - 3 } & Para trás & Para frente \\
\hline Algodão & 0,90 & 0,72 \\
Arroz & 0,84 & 1,13 \\
Milho & 0,90 & 0,75 \\
Soja & 1,09 & 0,75 \\
\hline
\end{tabular}

Fonte: SEPLAN/MT (2011).

O indicador para trás reflete a sua demanda por insumos dentro da economia, e os índices para frente mostram a influência da atividade nas etapas seguintes na cadeia produtiva onde estão inseridas na economia analisada. $\mathrm{O}$ indicador sendo superior a um indica que há influência significativa da atividade dentro da economia analisada, em outras palavras, esses indicadores não consideram importação de insumo nem exportação de produção para avaliar o impacto na economia interna. 
No caso da soja, a sua relevância dentro da cadeia produtiva se dá no mercado de insumos agrícolas, e na atividade produtiva do arroz a sua influência é maior nas fases de industrialização e comercialização, que são etapas seguintes da agricultura e que estão inseridas na economia mato-grossense. Já no caso do milho, a sua relevância não foi identificada nem para as etapas anteriores da produção primária nem nas etapas seguintes.

A produção algodoeira não se mostrou com bom dinamismo para a economia de Mato Grosso, pois os indicadores foram inferiores a uma unidade. Isso se dá por causa dos insumos agrícolas serem em sua grande parte produzidos e adquiridos de outros estados ou via importação, e seu reflexo para frente não foi relevante devido a indústria têxtil ser pouco desenvolvida em Mato Grosso. Se a indústria têxtil do Estado fosse desenvolvida e a produção de insumos agrícolas fosse interna à economia de Mato Grosso, os indicadores de impactos para frente e para trás poderiam ser diferentes, indicando um potencial relevante para a produção algodoeira, que seria identificada como chave na cadeia produtiva e na economia mato-grossense.

Os indicadores de impactos econômicos (Tabela 3) mostraram que a produção de algodão, assim como a soja, em 2007 possuiu a capacidade de estimular a produção agregada do estado em $\mathrm{R} \$ 1,65$ a cada $\mathrm{R} \$ 1,00$ de algodão produzido. Isso indica que em relação à produção essas atividades possuem o mesmo poder de dinamizar o produto da economia de Mato Grosso. Porém, a influência maior foi da atividade produtiva do arroz, que obteve um indicador de 1,81, e o menor impacto foi da atividade produtiva do milho que possuiu um indicador de 1,54.

Tabela 3. Índice de Multiplicadores da Produção, Emprego e Renda dos principais setores agrícolas de Mato Grosso - 2007.

\begin{tabular}{l|c|c|c}
\hline \multirow{2}{*}{ Setores } & \multicolumn{3}{|c}{ Multiplicadores } \\
\cline { 2 - 4 } & Produção & Emprego & Renda \\
\hline Algodão & 1,65 & 1,11 & 1,28 \\
Arroz & 1,81 & 1,19 & 1,42 \\
Milho & 1,54 & 1,27 & 1,22 \\
Soja & 1,65 & 1,50 & 1,29 \\
\hline
\end{tabular}

Fonte: SEPLAN/MT (2011).

$\mathrm{Na}$ categoria emprego o setor do algodão apresentou o menor indicador que demonstrou um impacto de 1,11 de empregos gerados na economia do estado a cada 1 emprego gerado na produção algodoeira. Já o setor da soja é quem possuiu o maior efeito multiplicador de 1,50 empregos gerados na economia a cada 1 emprego gerado pela soja. 
Os demais setores do milho e do arroz apresentaram influência maior que do algodão em relação ao potencial na geração de empregos, pois obtiveram indicadores de 1,27 e 1,19 respectivamente.

No quesito renda, o algodão se destacou por possuir um efeito multiplicador de 1,28 que foi superior ao do milho $(1,22)$ e semelhante ao da soja $(1,29)$. Porém o setor do arroz ficou em evidência devido ao maior potencial na gearção de renda na economia de Mato Grosso em 2007 (1,42). Esse dado indica que a cada R \$ 1,00 de renda gerada no setor do algodão, $\mathrm{R} \$ 1,28$ será gerado em rendas para a economia como um todo.

O indicador do efeito multiplicador não demonstra a magnitude do impacto econômico que a atividade agrícola ocasionou na economia em 2007, para isso, é necessário mensurar esse impacto em termos de quantidade de empregos e valor monetário da produção e da renda. Apesar de uma atividade apresentar elevada significância em termos absolutos de sua produção, emprego e renda, o seu potencial em dinamizar a economia será representado pelos multiplicadores.

A partir da Figura 3, é possível verificar que as indústrias ligadas à produção de algodão são as de menor participação comparadas às principais indústrias de transformação de Mato Grosso. Com a participação de 3\% para a fabricação de produtos têxteis e de $6 \%$ para a confecção de artigos de vestuários e acessórios, nota-se que a quantidade de indústrias aptas para agregar valor à cotonicultura participam com $9 \%$ do total de indústrias do Estado, exatamente a metade do número de fábricas de produtos alimentícios, que estão relacionados com outras atividades da agricultura como soja, arroz e milho.

Figura 3 - Quantidade de indústrias de transformação e participação relativa dos principais tipos de indústrias de transformação em Mato Grosso, em 2009.

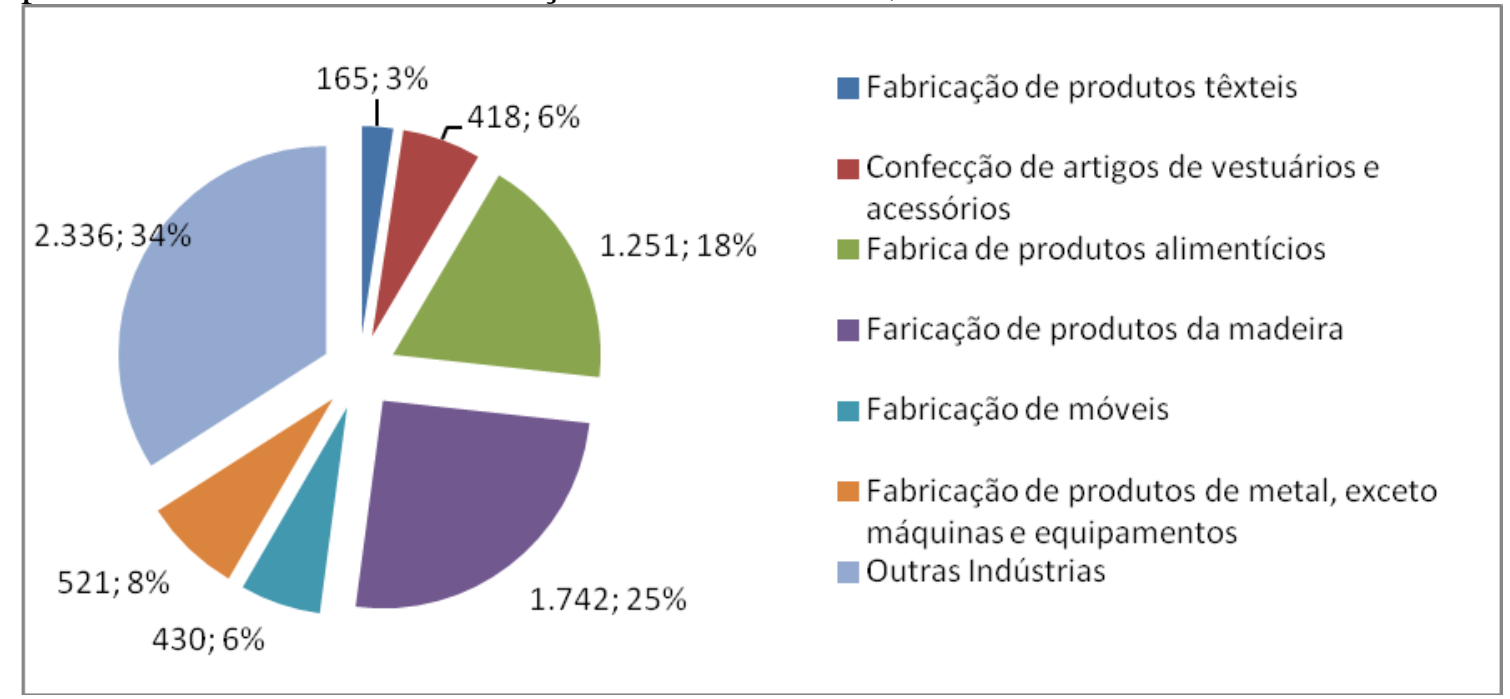

Fonte: Elaborado pelo autor com base em SEPLAN/MT (2012). 
Os setores agrícolas analisados na tabela 4 possuem uma estrutura produtiva semelhante: são atividades produzidas em larga escala, com pouca mão-de-obra direta, usam máquinas e equipamentos avançados, e utilizam insumos químicos. Grande parcela desses insumos é importada, de outros estados ou países. Além disso, grande parcela da produção é destinada para a exportação ou é industrializada em outros estados, principalmente da região sudeste, com exceção da atividade produtora do arroz que apresentou índice para frente superior a um. Dessa forma, o que diferencia os setores e que possivelmente poderia explicar a diferença nos efeitos multiplicadores seria o fato da produção algodoeira ser a que menos se industrializa dentro da economia de Mato Grosso.

Tabela 4. Estimativas dos impactos econômicos das principais atividades agrícolas na economia de Mato Grosso na Produção, Emprego e Renda - 2007 (R\$).

\begin{tabular}{l|c|c|c}
\hline \multirow{2}{*}{ Setores } & \multicolumn{3}{c}{ Impactos Econômicos (R\$) } \\
\cline { 2 - 4 } & Produção & Emprego & Renda \\
\hline Algodão & $3.074 .555,97$ & $243.282,18$ & $959.765,17$ \\
Arroz & $448.175,80$ & $28.979,10$ & $118.980,44$ \\
Milho & $2.404 .764,01$ & $63.006,15$ & $871.638,91$ \\
Soja & $10.438 .166,18$ & $170.138,69$ & $3.159 .245,04$ \\
\hline
\end{tabular}

Fonte: SEPLAN/MT (2011).

Apesar dos impactos econômicos serem relevantes para a economia de Mato Grosso, a cotonicultura não demonstrou ser uma atividade com potencial para influenciar o produto da economia estadual e o nível de emprego, destacando-se somente na geração de renda. Isso é contraditório ao se analisar a atividade produtiva do algodão, pois a sua representatividade em relação à produção nacional é de 49,31\% e a sua geração de renda é superior ao do milho e do arroz e a sua geração de emprego é superior aos três setores comparados. Pode-se concluir com isso que a atividade algodoeira em Mato Grosso restringe os seus benefícios na agricultura e o seu potencial em estimular a produção ao longo da cadeia produtiva do estado é menor e que por isso, não pode ser considerada um setor chave.

A produção do algodão gerou um impacto de $\mathrm{R} \$ 3.074 .555,97$ no valor de produção na economia de Mato Grosso no ano de 2007, sendo superior ao impacto do arroz e do milho. A soja, pela sua significativa atuação no Estado, foi superior ao algodão nos impactos da produção. 
Em relação aos empregos gerados, o impacto do setor algodoeiro foi superior às demais atividades pelo fato da cotonicultura ser a atividade que mais emprega pessoas dentre as atividades analisadas. Por fim, em relação à renda o setor da soja destaca-se, devido ao seu volume de renda gerada pela atividade ser superior aos demais setores, inclusive da cotonicultura. Entretanto em seguida, vem o setor de algodão que gerou um impacto na renda agregada de Mato Grosso de $\mathrm{R} \$$ 959.765,17. Apesar dos impactos econômicos significativos para a economia do estado, principalmente comparadas com as demais atividades agrícolas analisadas, a produção algodoeira não apresentou indicadores que a colocasse como uma atividade chave na cadeira produtiva nem como um setor capaz de dinamizar a economia mato-grossense. Deve-se isso ao fato de que a cadeia produtiva do algodão em Mato Grosso restringe-se à produção agrícola e pouco se faz em relação às etapas de industrialização. Acredita-se que incorporando demais elos como as indústrias de insumos agrícolas e de processamento do algodão, o setor possa se apresentar um potencial maior de influência no crescimento econômico estadual.

\section{CONSIDERAÇÕES FINAIS}

A atividade algodoeira foi analisada considerando por meio dos indicadores de ligação e de impactos, que evidenciaram uma cotonicultura não sendo chave para a cadeia produtiva de Mato Grosso e em alguns casos, com potenciais de impactos na produção, emprego e renda inferiores às demais atividades agrícolas analisadas. A produção de algodão estadual representa quase a metade da produção nacional, porém os demais elos da cadeira produtiva não estão incluídos na economia de Mato Grosso, e isso resulta numa atividade de baixa influência no crescimento econômico do estado.

Parte dessas conclusões se deve às limitações metodológicas da pesquisa, que considerou apenas o ano de 2007 e também por ser um estudo focado apenas nos impactos internos à economia de Mato Grosso. Outra questão importante são os impactos regionais causados pela cotonicultura que não puderam ser abordados devido às restrições da matriz insumo-produto.

Outro fator relevante seria a restrição da análise referente ao impacto econômico na produção, emprego e renda apenas com os indicadores do Efeito Multiplicador. Esses indicadores mostram o potencial que a atividade possui em influenciar na economia como um todo, mas não mostra a magnitude do impacto, que é dado também pelo Valor da Produção, Número de Empregados e Renda gerada na atividade estudada. A existência de 
outras matrizes possibilitaria realizar uma análise dinâmica do setor, identificando as alterações na estrutura produtiva do Estado.

A atividade sojicultora apresenta relevância para o Estado de Mato Grosso e por isso, seus impactos na produção e renda foram superiores. Isso demonstra uma necessidade em aplicar a mesma metodologia em comparação com outros setores agrícolas e nãoagrícolas, com a finalidade de demonstrar e quantificar a relevância desse setor na economia de Mato Grosso. Outra recomendação para futuros trabalhos é utilizar a Matriz Insumo-Produto de outras regiões para realizar um estudo comparativo e identificar semelhanças e diferenças entre as economias dos estados de perfil idênticos.

\section{REFERÊNCIAS BIBLIOGRÁFICAS}

BATALHA, Mário Otávio. Noção de Commodity System Approuch (CSA) e conceito de agronegócio. In: BATALHA, M. O. (Org.). Gestão Agroindustrial. São Paulo: Atlas, 2007.

FIGUEIREDO, Margarida Garcia de. Agricultura e Estrutura Produtiva do Estado do Mato Grosso: uma análise insumo-produto. 2003, 188f. Dissertação (Mestrado em Ciências, área de concentração: Economia Aplicada) - Escola Superior de Agricultura "Luiz de Queiroz", Universidade de São Paulo, Piracicaba, 2003.

IBGE (Instituto Brasileiro de Geografia e Estatística). Produção Agrícola Municipal. Disponível em: $<$ http://www.sidra.ibge.gov.br/bda/acervo/acervo2 $. a s p ? e=v \& p=P A \& z=t \& o=11>$. Acessado em 15 de jan de 2012.

JOHNSTON, Bruce F.; MELLOR, John W. The role of agriculture in economic development. The American Economic Review, Vol. 51, sep, 1961.

KEYNES, John Maynard. Teoria Geral do Emprego, do Juros e da Moeda. São Paulo: Atlas, $13^{\circ}$ ed. 2007.

LEWIS, Arthur. O modelo de desenvolvimento econômico com oferta ilimitada de mão-de-obra. Disponível em<>. Acessado em 12 de dez. de 2011. 
MENDES, Judas T. G.; BATISTA Jr., João P.; Agronegócio: Uma abordagem sistêmica. São Paulo: Pearson, 2007.

ROSSETTI, José Paschoal. Contabilidade Social. São Paulo: Ed. Atlas, 7ª ed, 1992.

SEPLAN/MT (Secretaria de Estado de Planejamento e Coordenação Geral de Mato Grosso). Construção da Matriz Insumo-Produto Inter-regional Mato Grosso e Resto do Brasil - 2007. 2011.

SEPLAN/MT (Secretaria de Estado de Planejamento e Coordenação Geral de Mato Grosso). Anuário Estatístico de Mato Grosso 2010. Disponível em:< http://www.anuario.seplan.mt.gov.br/2010/>. Acessado em 02 de abr de 2012.

SOUZA, Nali de Jesus de. Desenvolvimento Econômico. São Paulo: Atlas, $5^{\circ}$ ed, 2005.

ZYLBERSTAJN, Decio. Conceitos Gerais, Evolução e Apresentação do Sistema Agroindustrial. In: ZYLBERSTAJN, Decio; NEVES, Marcos Fava (Org). Economia e Gestão dos Negócios Agroalimentares. São Paulo: Pioneira, 2000, p. 1-21. 